\title{
Hereditary chronic pancreatitis
}

INSERM

\section{Source}

INSERM. (1999). Orphanet: an online rare disease and orphan drug data base. Hereditary chronic pancreatitis. ORPHA:676

Hereditary chronic pancreatitis (HCP), a rare inherited form of pancreatitis is defined as recurrent acute pancreatitis and/or chronic pancreatitis in two first-degree relatives or 3 or more second-degree relatives in 2 or more generations, for which no predisposing factors are identified. HCP is characterized by irreversible damage to both exocrine and endocrine components of the pancreas. 